\title{
ESTADO E CONTROLE NAS PRISÕES
}

\author{
Analia Soria Batista*
}

\begin{abstract}
Este artigo analisa o problema da produção do controle e da ordem em prisões brasileiras, utilizando as perspectivas histórica e sociológica, e levanta a hipóteses de que, no Brasil, convivem duas modalidades de construção da ordem e do controle nas prisões. Uma delas, minoritária, baseia-se na prerrogativa do Estado na gestão do dia a dia prisional. A outra é relativa à negociação da pacificação do presídio entre o Estado e as lideranças dos presos. Embora, no primeiro caso, a prerrogativa do Estado possa ser vinculada às condições institucionais adequadas e, no segundo (negociação entre o estado e as lideranças dos presos) às condições precárias dos presídios, como superlotação, número reduzido de agentes penitenciários, entre outros, a análise apontou que ambas as modalidades traduzem formas de relacionamentos e interações sociais historicamente produzidas entre o Estado e a sociedade, que remetem à fundação da República, recriadas através do habitus dos atores sociais, não se restringindo exclusivamente ao espaço social das prisões.

PALAVRAS-CHAVE: prisões, Estado, agentes penitenciários, controle, ordem.
\end{abstract}

\section{INTRODUÇÃO}

Um aspecto frequentemente apontado, nos estudos sobre as prisões brasileiras, é a perda quase total do controle do Estado sobre a vida cotidiana dos detentos nos estabelecimentos. Ao "descontrole" ou "desordem" observados corresponderia a emergência de um "controle" ou "ordem", exercido pelos próprios internos, organizados em coletivos denominados "comandos", com suas lideranças sempre violentas, que disputam poderes e hierarquias impondo regulamentações sobre o dia a dia da prisão.

Em estudo sobre as rebeliões nos presídios entre os anos de 1990 e 2001, Sallas (2006, p. 3) indica que esses episódios revelaram

uma baixa capacidade do Estado em controlar a dinâmica prisional, em fazer valer princípios fundamentais de respeito à integridade física dos indivíduos presos, permitindo que grupos criminosos imponham uma ordem interna sobre a massa dos presos.

* Doutora em Sociologia. Professora do Instituto de Ciências Sociais - ICS, Departamento de Sociologia da Universidade de Brasília.

Campus Universitário Darcy Ribeiro, Asa Norte. Cep: 70910-900. Brasília -DF - Brasil. analiasoria@unb.br / trrab526@terra.com.br
Nesse contexto, o autor levanta a hipótese de que

o Estado, representado pelo corpo dirigente local, não tem mais o controle efetivo da maioria das prisões sob sua responsabilidade, conseguindo assegurar a paz interna somente pela delegação do dia a dia prisional às lideranças desses grupos criminosos.

Assim, o controle dentro das prisões ou é exercido pelo Estado, que impõe a ordem, ou pelos internos, significando, nesse último caso, que o Estado perdeu o controle efetivo. É nesse sentido que as noções de "controle e descontrole" e "ordem e desordem" são construídas como polaridades analíticas, isto é, processos sociais dicotômicos e ahistóricos. Nessa direção, e fazendo referência ao problema da segurança pública no Brasil, Soares e Guindani (2007) criticam a abordagem positivista da experiência brasileira sobre a barbárie, isto é, a explicação desse processo a partir das dicotomias de ordem versus anomia, sendo a primeira idealizada e a segunda observada como patologia, explicada em função de desvios ou transgressões, independentemente dos processos geradores da ordem. 
Com base em uma pesquisa empírica comparativa realizada durante os anos de 2006 e 2007 em prisões do Distrito Federal e de Goiás junto aos Agentes Penitenciários e os internos, cujos objetivos foram mais amplos e diversificados, tentarei aqui esboçar uma leitura, ainda preliminar, sobre o problema do controle e da ordem nas prisões. ${ }^{1}$ Minha hipóteseé a de que, no Brasil, convivem duas modalidades de construção da ordem e do controle nas prisões. Uma delas, minoritária, baseada, principalmente, sobre a prerrogativa do Estado na gestão do dia a dia prisional. ${ }^{2}$ A outra, baseada sobre a negociação da pacificação do presídio entre o Estado e as lideranças dos presos. Embora, no primeiro caso, a prerrogativa do Estado possa ser vinculada às condições institucionais adequadas e, no segundo (negociação entre o estado e as lideranças dos presos), às condições precárias dos presídios, como superlotação, número reduzido de agentes penitenciários, entre outros. Consideramos que ambas as abordagens traduzem formas de relacionamentos e interações sociais historicamente produzidas entre oEstado e a sociedade, recriadas através do habitus dos atores sociais e que não se restringem ao espaço social das prisões.

O habitus é entendido por Bourdieu (1983, p. 46, 47) como

... um sistema de disposições duráveis e transponíveis que, integrando todas as experiências passadas, funciona, em cada momento, como uma matriz de percepção, apreciação e ação e torna possível cumprir tarefas infinitamente di-

${ }^{1}$ A pesquisa, coordenada pelas professoras Lourdes M. Bandeira e Analía Soria Batista, foi financiada pela Secretaria Nacional de Segurança Pública (SENASP- MJ). No Distrito Federal, a investigação baseou-se na prisão masculina denominada Centro de Internamento e Reeducação (CIR), e na prisão feminina, denominada Colmeia. Ėm Goiás, o campo empírico foi o complexo Penitenciário Odenir Guimarães, de Aparecida de Goiás, e o presídio feminino Centro de Inserção Social (CIS) Consuelo Nasser. Realizaram-se observaçốes etnográficas, entrevistas em profundidade com agentes, diretores, psicólogos e familiares dos internos. Também foram realizados grupos focais com os internos e as internas. Foram feitas em torno de 100 entrevistas e 19 grupos focais, os quais permitiram interagir com 85 internos e internas.

${ }^{2}$ Os Agentes Penitenciários de Brasília são policiais (Polícia Civil) que desempenham a função de agentes penitenciários. Isso significa que seus salários são significativamente superiores aos dos agentes de outros Estados da Federação, que não são policiais civis, como é no caso de Goiás. Agregam-se a isso outras condições, como as características do prédio, o estilo de gestão penitenciária adotado, os recursos disponíveis e as estratégias de segurança e inteligência utilizadas que permitem manter as iniciativas de controle do Estado dentro da prisão. ferenciadas, graças à transferência analógica de esquemas adquiridos em uma prática anterior.

Ainda, o habitus é experimentado e posto em prática na medida em que as conjunturas de um campo o estimulam. Campo seria um espaço de relações entre grupos com distintos posicionamentos sociais, espaço de disputa e jogos de poder. Segundo Bourdieu, a sociedade é composta por vários campos, vários espaços dotados de relativa autonomia, mas regidos por regras próprias. O habitus, produto da história, se configura como um sistema de disposições aberto, que é afetado por novas experiências e, nesse sentido, criado e recriado.

Na análise, proponho-me a discutir a produção de determinadas relações e modos de interação entre o Estado e a sociedade no processo de constituição da República brasileira, processos sociais que contribuíram para criação e recriação de disposições nos atores sociais, isto é, esquemas de percepção, apreciação e ação que, de modo singular, continuam presentes na atualidade, revelando antagonismos, contradições, opressões e poderes no espaço da instituição prisional.

Assim, pois, a instituição prisional constitui cenário privilegiado de manifestação de complexos processos de controle social e de produção da ordem, traduzidos em modalidades de relações e interações sociais historicamente produzidos e reproduzidos através do habitus dos atores sociais. Trata-se, no entanto, de dinâmicas sociais que excedem esse espaço social em suas manifestações, consequências e significados. Por isso, embora considere a prisão espaço privilegiado para compreender as dinâmicas de controle social e de construção da ordem na atualidade, o estudo pretende apontar para a importância de analisar o fenômeno que nos ocupa sem restringi-lo à esfera jurídica ou penal e institucional.

\section{ESTADOE SOCIEDADE}

Para compreender o fenômeno do controle e da produção da ordem atualmente, no interior das prisões brasileiras, proponho abandonar tem- 
porariamente o espaço institucional da prisão para refletir sobre um momento considerado chave na constituição das relações entre o Estado brasileiro e a sociedade: a fundação da República. No centro desse debate, encontra-se o problema da construção da cidadania.

Carvalho (1987) aponta que a República brasileira conseguiu se consolidar com um mínimo de participação eleitoral, excluindo o movimento popular do governo e da cultura. ${ }^{3}$ Segundo o autor, o vazio da exclusão política e cultural foi paulatinamente preenchido pela produção de novos ordenamentos, ou "outras" repúblicas, por parte das classes populares. Essas outras repúblicas acabaram produzindo suas próprias regulamentações e modalidades de resolução dos conflitos e criando comunidades de sentimentos em torno de suas manifestações culturais. Também produziram modos singulares de contato e articulação com o ordenamento jurídico estatal, representado pelas leis da República, os burocratas da esfera jurídica, a polícia e os políticos, isto é, com os representantes do poder.

O déficit de cidadania que feudalizou juridicamente a sociedade brasileira propiciou a proliferação de modos singulares dos não-cidadãos se relacionarem com o poder e com os poderosos, e vice-versa. Indiferença, pragmatismo para conseguir favores dos poderosos e violência, quando se considerava que o Estado pretendia regular os direitos e valores tidos pelas classes populares como fora de sua órbita de poder, caracterizaram e parecem caracterizar ainda as complexas relações entre a sociedade e o Estado no Brasil.

Desse modo, junto com Carvalho (1987), é possível refletir que, em face da ausência de direitos, isto é, do déficit de cidadania que se instaurou paulatinamente, até se consolidar como um traço peculiar da sociedade brasileira, foi sendo produzida uma visão cínica e irônica do poder. Sem espaço sociopolítico para a sua participação pública, as classes populares construíram seus modos específicos de participação social nos bair-

3 Mas, o fato de as elites se apegarem aos costumes europeus da belle époque não impediu a aproximação dessas classes com a cultura da elite, modelando novas realidades sociais, assim como uma nova identidade coletiva. ros, nas associações, nos grupos étnicos, e assim por diante. Desse modo, expandiu-se uma variedade de ordenamentos jurídicos que coexistiam, competiam ou conflitavam com o ordenamento jurídico estatal. Como aponta Carvalho, a complexa trama das relações entre as classes populares e o poder acabou se traduzindo num conluio entre "ordem e desordem", "lei e transgressão".

Até o presente, o fenômeno do pluralismo jurídico associado ao déficit de cidadania constitui um traço marcante da sociedade brasileira (Carcova, 1998). Na década de 70 do século passado, Sousa Santos (1980) discutiu essa questão focando sua análise no processo histórico, jurídico e social de surgimento de uma favela do Rio de Janeiro. A situação inicial de ilegalidade da favela e as ações violentas do Estado para desalojar os moradores com a força policial foram fatores fundamentais (embora não os únicos) para se compreenderem as razões do aparecimento, muito embora frágeis, de formas singulares de resolução dos conflitos na comunidade, isto é, de outro ordenamento jurídico. Em síntese, na medida em que o poder judiciário estava vedado para os moradores da favela, pois ela resultava de processos de ocupação ilícitos à luz do direito oficial, a comunidade produziu seu próprio direito, o direito de Pasárgada.

Consideramos que a análise sobre o exercício do controle do Estado nas prisões precisa levar em conta que a ordem que se consegue manter nessas instituições, seja ela percebida como "perda de controle por parte do Estado", ou como "controle efetivo por parte do Estado" pode ser considerada como caudatária de determinados habitus ou disposições dos atores sociais. Isso significa que a dinâmica dessa ordem, nos processos de interação entre os agentes penitenciários e os internos, é produzida e recriada sobre a negação histórica do reconhecimento do status de cidadãos desses últimos e sobre uma visão irônica e cínica do poder por todos compartilhada.

De outro lado, esses não-cidadãos são cidadãos de "outras repúblicas" que coexistem com a república hegemônica, caudatários de suas regulamentações, sentimentos, emoções e referências 
culturais. Caudatários de habitus produzidos nas modalidades históricas de relacionamentos e interações com os representantes do poder estatal. De uma parte e de outra, do lado do Estado e do lado dos internos, o déficit de cidadania colocado a nu no espaço social da prisão poderá ser preenchido pelo que resta de práticas como favoritismo, corrupção, tortura, delação e, é claro, também da aplicação das leis. Por isso, talvez resulte inadequado tomar a aparência de ordem ou a aparência de desordem nas prisões pela realidade da produção do controle e da ordem efetiva. Essa última resulta de enquadramentos e transgressões que envolvem representantes do Estado, como agentes, policiais, juízes, advogados, entre outros, e os próprios internos.

Assim, a fragilidade dos direitos ou a sua negação tem como contrapartida a substituição por modalidades singulares de relacionamento e interação social entre os envolvidos nesses processos sociais. Tais modalidades não podem ser ocultadas ou invisibilizadas pela invocação dos conceitos de "sociedade disciplinar" de Foucault (1987) ou de "instituição total" de Goffman (2003). Há o ressaibo da negação histórica do status de cidadania para as classes populares brasileiras pelos poderosos e há, nelas, a presença material e simbólica das "outras repúblicas", construídas no vazio da negação da participação pública e dos direitos sociais. Há, pois, habitus estimulados da sociedade brasileira atualizados no espaço social da prisão.

\section{MODALIDADES DE ORDEM E CONTROLE NAS PRISÕES}

O estudo realizado permitiu identificar duas modalidades de construção da ordem e do controle nas prisões. No caso da prisão analisada no Distrito Federal, o controle sobre o cotidiano aparece como prerrogativa do Estado; na prisão estudada em Goiás, como produto de um processo de negociação entre os agentes que representam o Estado e os internos, realizado através de suas lideranças. Trata-se, prima facie, de modos diferenciados de articulação entre os representantes do Estado e os dos internos que se expressam em interações e relações sociais peculiares e complexas.

A análise sobre cada um dos casos das prisões, que denominarei Prisão do DF e Prisão de Goiás, estrutura-se em dois momentos. O primeiro apresenta observações extensivas sobre a prisão, visando a contextualizar espacial e esteticamente os cenários das relações e interações sociais entre os agentes e os internos. O segundo descreve e analisa a dinâmica das relações e interações sociais a partir do estudo das regulamentações da vida cotidiana nas prisões, focadas na intimidade, apontando para seus antagonismos, contradições, oposições, opressões e poderes. Nas prisões, a intimidade dos internos se constitui em espaço político, arena de disputa, isto é, da imposição e negociação de regras que visam ao estabelecimento de um cotidiano submetido ao controle. É desse modo que as práticas sociais relativas às regulamentações sobre a intimidade revelam as lutas pelo poder entre os agentes e os presos e entre os próprios internos. Giddens (1998) considera a intimidade como esfera da vida social onde acontecem as relações pessoais, os afetos, a vida erótica, os amores filiais ou fraternais com os outros significativos.

\section{CONTROLEE ORDEM COMO PRERROGATIVA DO ESTADO: a prisão e as regulamentações da vida cotidiana em prisão do Distrito Federal}

Até pouco tempo, a penitenciária masculina do Distrito Federal localizava-se relativamente distante do meio urbano. ${ }^{4}$ Com relação ao denominado Plano Piloto da cidade de Brasília, ela distava em torno de $25 \mathrm{~km}$. Mas a cidade se expandiu e, atualmente, ela se localiza perto de uma diversidade de condomínios de classe média e de uma vila de trabalhadores pobres, tradicionalmente classificada como "cidade-dormitório". Apesar da pro-

${ }^{4}$ Comumente, as prisões são alvo de processos de banimento que permitem mantê-las afastadas dos locais mais urbanizados, para preservar os cidadãos livres da "nocividade" que uma parte significativa da sociedade lhes atribui. 
ximidade desses conglomerados urbanos, o acesso até a unidade estudada é difícil: é necessário descer, seguindo um caminho de asfalto que serpenteia entre os morros. Parece estar localizada "nas profundezas da terra". De um lado, apenas os morros a rodeiam; do outro, eles foram transformados pelas construções precárias da vila de trabalhadores pobres.

Interessante se torna apontar que as grades e alambrados que rodeiam essa unidade, não conseguiram, inicialmente, prender a nossa atenção. Acostumados como estamos à paisagem urbana de condomínios e casas gradeadas, a penitenciária se apresenta muito mais como continuidade do estilo de urbanização que vem sendo adotado na cidade de Brasília e suas redondezas, nas últimas décadas, como uma ruptura da geografia possível. Em razão disso, produz-se uma contradição na experiência do observador: o sentimento de ruptura é produzido pela localização da penitenciária; e a experiência de continuidade é relativa à paisagem construída pelos arames e grades que a rodeiam.

São esses aspectos mais exteriores que permitem, inicialmente, observar a penitenciária como continuidade e ruptura em relação à sociedade que a cria, mantém e reproduz. Além disso, certas continuidades e rupturas entre a rua e a penitenciária são construídas discursivamente com base no senso moral dos agentes. O discurso desses agentes "divide" a sociedade em dois grupos bem definidos: os criminosos e os normais. Prima facie, os criminosos pertencem à penitenciária, e os ditos “normais” à sociedade dos homens livres.

No interior da prisão masculina, um agente entrevistado medita e observa: "... há um mundo lá fora e há um mundo aqui dentro...”. Essa expressão é indicativa da construção discursiva sobre duas moralidades: a do mundo dos corretos e a dos incorretos, a dos transgressores, que orientam seu comportamento por prescrições diferentes das impostas pela ordem jurídica, e a dos que vivem em harmonia com essa mesma ordem. No discurso proferido, cada um desses mundos aparece, discursivamente, como uma totalidade de coisas que pertencem a domínios diferentes. As- sim, a sociedade e a penitenciária podem ser construídas como territórios peculiares e distantes, acenando para uma ruptura entre a sociedade e o mundo dos presídios. Como já indicado, a localização geográfica, "nas profundezas da terra", colabora para a construção dessas fronteiras simbólicas, traduzindo, de certa maneira, a experiência radical de se trabalhar na instituição e, evidentemente, a do encarceramento. " $O$ mundo aqui dentro é o dos transgressores, rotulados como criminosos, o pior da sociedade", afirma um agente. ${ }^{5}$ Mas também o discurso dos agentes indica certas continuidades entre a rua e a penitenciária. O interior da penitenciária é construído como continuidade de uma rua considerada perigosa:

- “... a penitenciária, no período diurno, está em total movimento. Durante a noite, os detentos são colocados nas celas, mas aí, quem vai entrar num pavilhão de 20 celas? Tem o mesmo perigo que a gente entrar numa quadra perigosa. Você pode correr o risco de alguém, lá na última cela, pedir um socorro médico e as primeiras celas já estarem devidamente preparadas com facas artesanais, por exemplo."

Os pavilhões assemelham-se a ruas perigosas da cidade, caracterizadas pelas armadilhas, os assaltos, os estupros: eis ai a continuidade entre a cidade e o presídio. O presídio é construído como continuidade da parte abjeta da cidade.

Uma guarita serve de passagem para o ingresso nas instalações da prisão. Para entrar, é necessário atravessar um molinete e registrar-se no balcão, deixando em escaninhos certos objetos, como telefones celulares, por exemplo. Não se ingressa sem ser conduzido por um agente. À direita, observa-se um bloco térreo, onde funciona a administração da prisão; em frente, há o prédio principal, lugar onde se localizam os pavilhões com suas celas e o setor de ensino da prisão. Na entrada do prédio principal, há um cartaz com a seguinte inscrição: "Jesus te ama". Debaixo do cartaz, um agente armado e com várias algemas dependuradas no cinto parece estar aguardando algum comando, distraidamente. Esse prédio tam-

5 Esses socialmente apontados como os “piores" serão alvo de novo julgamento classificatório no interior da instituição, sendo produzido um grupo social mencionado como "os piores dos piores" do presídio, aqueles finalmente destinados ao isolamento do "Pavilhão de Segurança Máxima (PSM). 
bém possui uma guarita onde é necessário se registrar. Depois dela, visualiza-se um corredor estreito e comprido, em cujas celas de grade se observam os internos recém-chegados ao lugar ou em vias de serem transferidos de setor. Tecnicamente, aguardam a triagem.

Ao entrar no prédio principal, o agente, com voz firme, exige dos internos virarem de costas, ficarem de cócoras, longe das grades, olhando para a parede. Algemados, eles se movimentam sem inquietação ou curiosidade pela nossa presença. São apenas corpos que se movimentam.

Ingressamos na prisão junto com os agentes, cujos corpos se dispõem, como escudos protetores, entre nós e os internos, face à proximidade das celas transitórias que os albergam. Essa performance dos agentes do Estado visa a comunicar que o local é considerado perigoso. Eles enfatizam que o lugar oferece riscos, situação que contribui para criar em nós um sentimento de expectativa, curiosidade e certo nervosismo. No corredor, cruzamos com alguns internos que trabalham dentro da prisão. Quando nos visualizam, param e automaticamente ficam de costas, olhando para a parede, evitando-nos, e é desse modo que nos deixam passar, roçando seus corpos no corredor estreito. Pouco depois, passamos pelo parlatório, lugar onde os internos fazem sexo com suas espoatendimento social e sanitário dos internos e que encaminha suas solicitações, escolhendo aquelas que avalia como prioritárias.
As paredes da prisão estão descascadas. Por vezes, observamos água no piso dos corredores, como se houvessem limpado o local recentemente. Percebe-se um cheiro estranho, azedo, que lembra o dos hospitais públicos.

Chegamos a um pátio. Dois agentes munidos com cassetete de madeira (os que nos acompanham têm cassetetes comuns) observam os internos do "posto de serviço". ${ }^{7}$ Os internos tomam banho de sol. Um Agente explica:

- “... durante o dia, ninguém pode ficar nas celas e, à noite, ninguém pode ficar no pátio. A rotina do detento é assim por causa da segurança, não porque se pense que ele precisa de "banho de sol”, mas para evitar confabulações".

Entre os internos e nós há a performance dos agentes e as grades. Os internos conversam em grupos, mais ou menos numerosos. Parecem muito jovens, há negros, mulatos e brancos, esses últimos em menor proporção. Todos com a cabeça rapada. Usam vestimentas comuns, shorts, camisetas e chinelos, e alguns exibem tatuagens nos braços. As paredes descascadas do pátio apresentam desenhos infantis tradicionais, de Walt Disney. Logo que somos percebidas, os internos nos olham, juntam-se e comentam. Os agentes se apressam a dizer que, na cadeia, é necessário evitar a circulação de pessoas e as aglomerações. Também experimentamos dificuldades para escutar o que os agentes nos dizem, pois há barulho constante, vozes, conversas.

Aproveitando que os internos permanecem reunidos no pátio, visitamos as pequenas e sufocantes celas. Observamos que, do lado direito delas, há uma estrutura de concreto com um colchão e roupa de cama. Essas celas abrigam dois ou três internos, mas há apenas uma cama. Do lado esquerdo, uma escada de concreto conduz ao banheiro. No lugar onde deveria estar o chuveiro, há uma garrafa de plástico. Não existe vaso sanitário, apenas um buraco. Uma meia parede separa o ba-

O "posto de serviço" é o local destinado aos agentes encarregados da vigilância dos internos durante o banho de sol no pátio. 
nheiro do lugar onde os internos dormem e realizam suas refeições.

Nas paredes das celas, há desenhos de armas de fogo e de Jesus Cristo. Nelas, há diversas inscrições:

- "Viciados, vida louca, paz, liberdade."

- "Roubaste minha alma."

- "Você venceu este deserto, fui e nunca mais."

- "Apocalipse."

- "Porque para Deus nada é impossível."

- "Adoro poder durar uma noite mais a alegria vem pela manhã."

- "Se Deus está por nos, quem será contra nos? Ninguém."

"Você não sabe como é caminhar na mira de uma HK."

É nessa prisão que o Estado tem assumido a prerrogativa de regulamentar uma parte importante da vida cotidiana dos internos. A jornada é organizada em função de rotinas carcerárias, tais como banho de sol, ${ }^{8}$ recolhimento, ${ }^{9}$ confere,${ }^{10}$ visitas de familiares e relacionamentos sexuais. Essas ações são orientadas por normas e procedimentos justificados pelo discurso a respeito da necessidade de manutenção da segurança, isto é, de evitar as "armadilhas" dos internos. Tais rotinas são constituídas por exigências que dizem respeito ao disciplinamento do corpo dos internos, tais como evitar olhar nos olhos dos superiores, ou caminhar com a "cabeça baixa e as mãos atrás", entre outras. Tais exigências podem motivar questionamentos. Em que medida o disciplinamento da fala, dos gestos e do corpo dos internos é um elemento de segurança? Em que medida constitui um tipo de controle que objetiva a humilhação do interno?

Embora a regulamentação de uma parte significativa da vida íntima dos internos constitua prerrogativa do Estado, há espaços de intimidade não

${ }^{8} \mathrm{O}$ banho de sol é o momento em que os internos são conduzidos aos pátios da prisão.

${ }^{9}$ O recolhimento é o momento em que os agentes procedem à retirada dos internos dos pátios, após o banho de sol. O recolhimento acontece mediado por uma série de procedimentos de segurança. Os internos têm de sentar-se no chão com as mãos atrás, enfileirados. A retirada acontece de forma ordenada, seguindo ordem dos agentes que os organizam, uma fila de cada vez.

${ }^{10} \mathrm{O}$ confere é o procedimento realizado por um agente, para conferir o número de presos por cela, após o recolhimento do banho de sol. submetidos ao controle dos agentes. Por exemplo, a sexualidade do interno é regulamentada até certo ponto. Há uma espécie de taylorização dos "encontros íntimos" dos internos, que têm direito, no caso dos homens, a receber esposas, namoradas e amigas, como apontado anteriormente. Mas a instituição estabelece determinadas interdições, como, por exemplo, a proibição de os homens fazerem sexo com outros homens nesses espaços formalmente "preparados" para o momento "higiênico" da atividade sexual. Assim, a versão oficial do encontro íntimo entre o interno e a mulher acontece sob o olhar atento do Estado, embora a versão não-oficial do encontro íntimo entre internos seja regulamentada pelos próprios internos. Há encontros sexuais consensuais e abusos. No caso desses últimos, conta-se com a indiferença dos agentes do Estado, existindo um acordo tácito no que diz respeito à menor interferência oficial possível nesse espaço de intimidade dos prisioneiros.

O comportamento do interno na prisão é alvo de monitoramento, recompensa e punição, realizados pelos agentes. De fato, os internos são classificados em quatro níveis, em função de seu comportamento: comportamento muito mau, ${ }^{11} \mathrm{com}$ portamento mau, comportamento bom e comportamento excelente. Essa classificação, que aponta o grau de sujeição dos detentos à ordem da instituição, constitui um parâmetro para eles terem acesso ou não às atividades educativas e de trabalho oferecidas na prisão. Na medida em que os direitos dos internos (educação e trabalho) não são garantidos pelo Estado, embora sejam estabelecidos como direitos na Lei de Execuções Penais (LEP, 1984), a classificação dos internos permite a distribuição desses bens escassos, ${ }^{12}$ que funcionam

${ }^{11}$ Os socialmente apontados como os "piores" serão alvo de novo julgamento classificatório no interior da instituição, sendo produzido um grupo social mencionado como "os piores dos piores" do presídio, aqueles finalmente destinados ao isolamento do Pavilhão de Segurança Máxima (PSM).

12 A LEP garante a remição penal por meio do trabalho, estabelecendo que, a cada três dias trabalhados, o preso tem o direito de descontar um dia da pena a ser cumprida. Ela reproduziu também, em seu conteúdo, a ideia de Estado democrático de Direito, segundo o qual o cumprimento da pena não pode implicar a perda ou minimização dos direitos fundamentais. Assim, o art. 41 da LEP estabelece os direitos elementares que devem 
como recompensas para quem aceita ou simula aceitar a sujeição à ordem institucional. Assim, na prática, a educação e o trabalho não constituem aspectos vinculados à lógica da reintegração social dos internos, embora a LEP pregue o caráter ressocializador da pena. Necessário enfatizar que um número significativo de agentes não acredita na possibilidade de reintegração dos detentos à sociedade. $^{13}$

Os internos classificados com "comportamento excelente", além de terem acesso às atividades educativas e de trabalho, residem em celasdormitórios, separados dos demais internos, pois são aqueles que colaboram com os agentes nas estratégias de inteligência destinadas a descobrir indícios de guetização na prisão, como por exemplo, a formação de comandos.

Essas classificações têm impacto na regulação da vida íntima dos internos, pois seus direitos à visita íntima, à relação com familiares, entre outros, dependerão da avaliação que os agentes façam de seu comportamento na prisão. É nesse jogo de sujeições e resistências entre agentes e internos que se podem manifestar diversas trocas, caracterizadas como transgressões: imposições, lealdades, delações, entre outros.

A regulamentação institucional de uma parte das relações e interações sociais do interno pressupõe a negação, no espaço da prisão, da procedência comunitária dos internos, ou seja, dos poderes, hierarquias e valores culturais próprios dos detentos. A prerrogativa do Estado em controlar o mais possível a vida cotidiana na prisão implica impedir sua guetização. Isso exige vigilância permanente para barrar qualquer indício de surgimento de comunidades, em suas formas organizativas, como quadrilhas, gangues ou comandos criminosos. Assim, o confinamento na prisão significa, até certo ponto, o confinamento da própria comunidade. A estratégia de impedir a formação de co-

ser assegurados aos que estão sob a responsabilidade do Estado: alimentação, vestuário, educação, instalações higiênicas, assistência médica, farmacêutica e odontológica.

${ }^{13}$ Para uma compreensão da nova cultura do controle e de sua relação com a descrença sobre as possibilidades de reintegração social dos detentos, ver Garland (2001). letivos dentro da prisão visa a manter os guetos ${ }^{14}$ à distância, para que sua lógica "poluída” não contamine o espaço social da prisão.

Nesse caso, os membros dos guetos, que foram arrancados de suas condições comunitárias de vida, são cotidianamente considerados pelos representantes do Estado como "inimigos" e "psicóticos". ${ }^{15}$ Essas representações dos internos mediatizam as relações e interações sociais com os agentes, orientados pelo pressuposto do "contato zero" com os internos. O pressuposto ideológico do ideal de igualdade, na prática, acaba sendo negado pelo habitus dos agentes, que fragiliza a consideração do interno como um sujeito digno de respeito, isto é, como um "igual”. Por essa via, verifica-se o desrespeito aos direitos dos que permanecem presos.

A prisão, como produção material e simbólica, resulta, na prática, de uma luta cotidiana dos representantes do Estado contra a possibilidade de "guetização" de seu ambiente. Não se pode afirmar até que ponto o Estado consegue, mas o endurecimento do controle e da disciplina, durante os últimos anos, abarcando inclusive os familiares dos presos, pode ser observado como resultante desse esforço para manter a prisão imune à ameaça do gueto.

De fato, observamos registros fotográficos do pátio da prisão antes do endurecimento do controle e da disciplina, realizados por agentes mais antigos durante as visitas dos familiares dos presos. Neles, só percebemos tendas feitas com len-

${ }^{14}$ Na sua forma completa, o gueto “... é uma instituição de duas faces, na medida em que serve a funções opostas para dois coletivos aos quais une em uma relação assimétrica de dependência. Para a categoria dominante, sua função é circunscrever e controlar, o que se traduz no que Max Weber chamou de "cercamento excludente" da categoria dominada. Para esta última, no entanto, trata-se de um recurso integrador e protetor na medida em que livra seus membros de um contato constante com os dominantes e permite colaboração e formação de uma comunidade dentro da esfera restrita de relações criada. O isolamento imposto pelo exterior leva a uma intensificação do intercâmbio social e cultural dentro do gueto. O gueto é o produto de uma dialética móvel e tensa entre a hostilidade externa e a afinidade interna que se expressa como uma ambivalência no nível do consciente coletivo." Wacquant (2004).

${ }^{15}$ Interessa destacar que a psicopatia é considerada relativamente rara; uma estimativa a situa em $10 \%$ ou menos da população prisional e em 3\% da população geral. Doren (1996). 
çóis, o que tornava invisíveis ou privativas as visitas. Hoje, a construção de tendas está proibida.

Nessa modalidade de ordem e controle prisional, a lógica da segurança predomina sobre a da reintegração social. $\mathrm{O}$ atendimento psicológico dos internos também é atrelado à lógica da segurança, na medida em que o profissional é instado a colaborar como informante e se integra às estratégias de inteligência, se necessário, chegando a interpelar os familiares dos detentos.

Da perspectiva do padrão das interações entre os agentes e os internos, observa-se que o Estado mantém o controle e impõe disciplina na prisão, regulando o mais possível a vida cotidiana dos detentos, classificando-os, interpelando-os para que colaborem e delatem. OEstado os recompensa quando "obedecem", facilitando-lhes o acesso à educação, ao trabalho, ao médico e a outras regalias, e os pune quando não se sujeitam, interditando-lhes o acesso ao trabalho e à educação, dificultando-lhes o acesso aos médicos e às regalias. $O$ Estado persegue sem descanso as possíveis lideranças, integrando, em suas estratégias de inteligência, outros profissionais do presídio, os internos que se sujeitam e os familiares que são manipulados. Nessas dinâmicas interativas, a troca de favores, o estabelecimento de lealdades, os favoritismos e transgressões das leis, entre outras, estão presentes.

\section{ORDEM COMO NEGOCIAÇÃO ENTRE ESTA- DO E INTERNOS: a prisão e a regulamenta- ção da vida cotidiana em prisão de Goiás}

Ingressamos no Complexo Penitenciário passando pelo lado direito de uma guarita. Os guardas pediram para descer do carro, para efetuar nosso registro. Depois, continuamos circulando de carro até ao setor da Administração, onde fomos recebidos pelo Diretor do Complexo. Posteriormente, outros funcionários nos encaminharam para a prisão objeto de nosso estudo, distante, aproximadamente, uns cem metros da Administração. Dentro do Complexo, é possível ir de uma unidade a outra a pé. O local é silencioso e arborizado, e por ele transitam alguns dos internos com roupas da cor azul, com a inscrição "Reeducando", na parte posterior. Alguns deles executam suas tarefas fumando maconha.

Para ingressar na prisão, temos de atravessar um portão de ferro, com dois ou três policiais monitorando essa movimentação. Somos informados de que essa prisão data da década de 60 . Observamos sinais de deterioração em seus muros e paredes, pintados de uma cor amarela envelhecida que teima em se desvanecer e descascar, deixando expostas as lajotas e pedaços de cimento. Vem à nossa mente a estética cinematográfica de Carandiru e as impressões sobre suas misérias, sujeiras, imprevisibilidades e inseguranças.

Observamos o pátio da prisão “de cima”, isto é, de uma passarela que nos permite uma visão relativa. Destaque-se que, durante o banho de sol dos internos, os agentes monitoram o pátio dessa mesma passarela. O pátio dos internos está dividido em dois espaços. De um lado há uma quadra de esportes e algumas árvores, onde os internos jogam futebol ou conversam, circulando livremente; do outro, há tendas armadas com lençóis, uma barbearia, um local para reunióes religiosas, mesas de sinuca, cantinas. Percebe-se, no entanto, que o pátio constitui um espaço de intimidade dos internos. A proliferação de cantinas (muitas) e mesas de sinuca constitui indícios da natureza das relações e interações sociais entre agentes e internos. Trata-se de "concessões" que segundo, os agentes, fazem da prisão "colônia de férias" ou "mamão com açúcar". Não foi possível visitar as celas, mas somos informados sobre a presença de DVDs e TVs a cabo em algumas delas. A privacidade e a intimidade dos internos permanecem nebulosas, pois não foram explicitadas para as pesquisadoras, como no caso da prisão estudada no Distrito Federal. Os agentes informaram "basta os presos quererem pra cadeia virar". Nesse primeiro momento associamos essa assimetria de poderes às condições ruins da infraestrutura da prisão.

Durante uma de nossas visitas, ocorreu um incidente revelador do padrão de relacionamento 
entre os agentes e os internos. Aguardávamos para realizar as entrevistas, caminhando pela parte externa do setor de Administração do Complexo Penitenciário, quando escutamos tiros, vindos da prisão objeto de nosso estudo. Nesse momento, um agente segurou meu braço, arrastando-me até o interior do prédio da Administração. Os funcionários se mostravam inquietos e nervosos, alguns corriam de um lado para outro, passando informações, situação que contribuiu para aumentar nossa expectativa. Desde a noite passada, tinham se espalhado ameaças de rebelião em várias unidades do Complexo Penitenciário, movimento promovido pelos internos da prisão que estávamos estudando. Em função disso, os Agentes Prisionais convocaram a Polícia Militar, que ingressou na unidade, enfrentando, segundo fomos informados, uma ala rebelde. Nessa operação, a polícia tirou dos internos celulares e drogas. Esse incidente revelou que o ingresso da PM na prisão foi a resposta dos representantes do Estado em face dos rumores de rebelião que tinham se espalhado. Para os agentes, isso indicava que os internos estavam dispostos a quebrar os acordos de pacificação estabelecidos em função de certas trocas. Observamos que a manutenção desses acordos resulta de uma frágil dinâmica, baseada em trocas, lealdades, ilegalidades, exercícios de dominação e opressão entre os internos e os agentes e entre os próprios internos.

Em Goiás, observou-se que o Estado delega uma parte importante da regulação da vida cotidiana da prisão aos próprios internos, organizados em grupos de natureza diversa, representados por lideranças. Essa delegação age como moeda de troca pela manutenção da paz nas instituições.

Esse modelo de controle do Estado na prisão revela as relações historicamente estabelecidas entre o Estado e a população pobre e excluída, muitas das quais permanecem até hoje. O Estado permite a "guetização" da prisão, isto é, aceita que a lógica social do "gueto" seja instalada no dia a dia da prisão e, em troca, exige a pacificação, isto é, a participação das lideranças dos detentos no controle das ações de fuga e das violências interpessoais entre os internos, entre outros as- pectos. Sob esses parâmetros, são estabelecidos pactos entre os agentes e as lideranças dos internos, caracterizados pela fragilidade e instabilidade, embora a sua ruptura seja percebida pelos atores sociais como exceção. Tem-se, nesse caso, o Estado reconhecendo a presença de “outras repúblicas”, produzidas pela população mais pobre, desprovida de cidadania.

A delegação da gestão da vida cotidiana da prisão às lideranças dos internos aparece justificada pelo discurso institucional sobre a necessidade de promover a reintegração social dos presos, o que exigiria incentivar o desenvolvimento de comportamentos responsáveis e disciplinados. Essa delegação teria esse sentido. Mas a reforma, a reabilitação e a redenção, não existem no "gueto".

A lógica do "gueto" reaparece na organização dos internos em "comandos", com suas lideranças que repartem o controle sobre diferentes aspectos do cotidiano da prisão. Por exemplo, a indicação das celas em que irão habitar os recémchegados, a estipulação de tarefas que deverão ser realizadas nas celas, pavilhões ou mesmo nas oficinas de trabalho. As lideranças escolhem os presos que irão trabalhar nessa ou naquela oficina, na cozinha, na lavanderia e assim por diante. As lideranças, inclusive, indicam quem será privilegiado com a administração da lanchonete, lugar estratégico para implementar o tráfego de drogas na instituição. Elas também decidem se um interno condenado por estupro poderá ter garantida sua permanência nos pavilhões, sem ser morto pelos outros internos, em troca de lealdade e servidão. Assim, também a dura lei da cadeia, produzida e reproduzida pelos internos, pode admitir exceções: tudo depende das circunstâncias, isto é, do que se possa obter em troca dessa flexibilidade.

O controle sobre espaços e atividades gera a imposição de todo tipo de constrangimento aos presos - contribuições financeiras, doação de alimentos, relacionamentos sexuais, colaboração com as atividades ilegais dentro e fora da prisão -, envolvendo, muitas vezes, os próprios familiares dos presos.

Nesse modelo, o considerado "réu” acabará se transformando em "reeducando", termo que 
contrasta com o de "inimigo", no modelo analisado para a instituição do Distrito Federal. Tudo parece indicar a prevalência, na prisão, da lógica da reintegração social. Mas, como assinalado, dificilmente a lógica do hipergueto conduzirá alguém à reintegração. Muito pelo contrário, a violência interpessoal, a brutalidade e a imprevisibilidade acabarão reforçando, em cada interno, a experiência coletiva do banimento.

\section{CONSIDERAÇÕES FINAIS}

Nas prisões estudadas, os agentes penitenciários ou prisionais reconhecem a presença do gueto e de suas complexidades, embora estabeleçam relações diferentes com seus membros. Em geral, para eles, na instituição do Distrito federal (DF), o gueto se constitui na principal ameaça para a segurança prisional, e, em função disso, as estratégias de inteligência se dirigem à identificação e destruição dos indícios de sua presença. A severidade das regulamentações do dia a dia da prisão pretende barrar o mais possível o surgimento das regulamentações dos internos. Esse foco autoriza modalidades de relacionamento e interações sociais com os internos que traduzem conluios, transgressões, opressões, interdições, delações, entre outras. Para os agentes de Goiás, o gueto constitui o recurso para a pacificação da prisão. Nela, a paz, no sentido de evitar fugas e mortes, é negociada com as lideranças dos presos em troca da liberdade para realizar negócios e regulamentar o dia a dia. Os acordos resultam frágeis e podem ser rompidos a qualquer momento. No primeiro caso, o Estado luta abertamente contra o gueto; no segundo, usa o gueto para pacificar o presídio, entregando para as lideranças a custodia dos internos mais fracos, que serão submetidos às regulamentações opressivas e violentas estabelecidas pelos que detêm o poder. Ambas as modalidades de controle e da ordem nas prisões expressam complexas dinâmicas sociais entre os representantes do Estado e os internos, com a presença de repressão, opressão, conluio, ordem e desordem, o que caracteriza o relacionamento histórico entre o Estado e os setores populares, atualizado no espaço social da prisão pelo habitus dos agentes. Tais relações também podem ser observadas em outros espaços sociais, nas favelas, nas feiras de pirataria, nas feiras informais, entre outros.

(Recebido para publicação em outubro de 2008) (Aceito em dezembro de 2008)

\section{REFERÊNCIAS}

BOURDIEU, Pierre. Sociologia. (organizado por Renato Ortiz). São Paulo: Ática, 1983.

CARCOVA, Carlos Maria. A opacidade do direito. São Paulo: Editora LTr, 1998.

CARVALHO, José Murilo de. Os bestializados: o Rio de Janeiro e a República que não foi. São Paulo: Companhia da Letras, 1987.

DOREN, Denis. Understanding and Treating the Psychopath. Northvale. NJ: Jason Aranson, 1996.

FOUCAULT, Michel. Vigiar e punir: nascimento da prisão. Petrópolis: Vozes, 1987.

GARLAND, David. The Culture of control: crime and social order in contemporary society. Oxford: Oxford University Press, 2001.

GIDDENS, Anthony. Las transformaciones de la intimidad: sexualidad, amor y erotismo en las sociedades modernas. Madrid: Ed. Cátedra, 1998.

GOFFMAN, Erving. Manicômios, prisões e conventos. São Paulo: Ed. Perspectiva, 2003.

SALLAS Fernando. As rebeliões nas prisões: novos significados a partir da experiência brasileira. Sociologias. Porto Alegre, v. 8 n. 16, p. 274-307, dez. 2006.

SOARES, Luís Eduardo; GUINDANI, Miriam. La tragedia brasileña, la violencia estatal y social y las politicas de seguridad necesaria. Nueva Sociedad. n. 208, 2007. p. 56-72.

SOUSA SANTOS, Boaventura de. Notas sobre a história jurídico-social de Pasárgada. In: SOUTO, Claudio; FALCÃO, Joaquim (Orgs.). Sociologia e Direito, São Paulo: Livraria Pioneira Editora, 1980. p. 88-89.

WACQUANT, Loïc, Que é gueto? Construindo um conceito sociológico. Revista de Sociologia e Política. Curitiba, n. 23,2004 . p . 155-164, 


\section{STATE AND CONTROL IN THE PRISON SYSTEM}

\author{
Analía Soria Batista
}

This paper analyzes the problem of the order and control production in Brazilian prisons, using the historical and sociological perspectives, and brings the hypotheses that, in Brazil, two modalities of construction of order and control in the prisons happen together. One of them, minoritary, is based on the State's prerogative of daily prisional administration. The other regards the negotiation of the prison pacification between the State and the prisoners' leaderships. Although, in the first case, the prerogative of the State can be linked to the appropriate institutional conditions and, in the second (negotiation between the State and the prisoners' leaderships) to such precarious conditions of the prisons, as overcrowding, reduced number of penitentiary agents, the analysis pointed out that both modalities translate forms of relationships and social interactions historically produced among the State and society, that go to the foundation of the Republic, recreated through the social actors' habitus, not limiting exclusively to the social space of the prisons.

KEYwORDS: prisons, State, penitentiary agents, control, order.

\section{ETAT ET CONTROLE DANS LES PRISONS}

\author{
Analía Soria Batista
}

Ce travail analyse le problème de la production du contrôle et de l'ordre dans les prisons brésiliennes en tenant compte des perspectives historique et sociologique et soulève l'hypothèse selon laquelle, au Brésil, il y a deux manières de construire l'ordre et le contrôle dans les prisons. L'une d'elles, minoritaire, est basée sur la prérogative de l'Etat pour la gestion quotidienne des prisons. L'autre est relative à la négociation de la pacification de la prison entre l'Etat et les leaders des prisonniers. Même si, dans le premier cas, la prérogative de l'Etat peut être liée aux conditions institutionnelles adéquates et, dans le deuxième cas (négociation entre l'état et les leaders des prisonniers), aux conditions précaires des prisons - telles que la surpopulation, le nombre réduit d'agents pénitentiaires, entre autres -, l'analyse montre que les deux modalités sont le reflet des formes de relations et d'interactions sociales historiquement produites entre l'Etat et la société qui remontent à la fondation de la République et qui sont recréées par l'intermédiaire de l'habitus des acteurs sociaux mais qui ne se limitent pas exclusivement à l'espace social des prisons.

MoTS-CLÉs: prisons, Etat, agents pénitentiaires, contrôle, ordre. 